\title{
Aporte de energia, composição e eficiência microbiana em bovinos alimentados com feno de capim-marandu e concentrado balanceados para diferentes ganhos de peso e potenciais de fermentação microbiana ${ }^{1}$
}

\author{
Rodolfo Marques de Brito ${ }^{2}$, Alexandre Amstalden Moraes Sampaio ${ }^{3}$, Alexandre Rodrigo \\ Mendes Fernandes ${ }^{4}$, Wignez Henrique ${ }^{5}$, José Wanderley Cattelan ${ }^{6}$, Karina de Souza Routman ${ }^{7}$ \\ 1 Parte da tese do primeiro autor apresentada à FCAV/Unesp/Jaboticabal. \\ 2 Unirp, São José do Rio Preto, SP. \\ ${ }^{3}$ Depto. Zootecnia/FCAV/UNESP, Jaboticabal, SP. Bolsista CNPq. \\ ${ }^{4}$ Pós-doutorando pela FCAV/Unesp/Jaboticabal. \\ ${ }^{5}$ Apta Regional, São José do Rio Preto, SP. \\ ${ }^{6}$ Depto. de Clínica e Cirurgia Veterinária/FCAV/Unesp, Jaboticabal, SP. \\ ${ }^{7}$ Mestre pela FCAV/Unesp/Jaboticabal.
}

RESUMO - Um experimento foi realizado com o objetivo de avaliar o aporte de energia, a composição de bactérias e a eficiência microbiana por tourinhos Santa Gertrudes canulados no rúmen e no duodeno alimentados com dietas compostas de feno de capim-marandu e concentrado. Empregou-se o delineamento em quadrado latino $4 \times 4$, no qual os tratamentos foram concentrados ajustados para ganho de peso corporal (GPC) diário de 0,5 e 1 kg/animal e potencial de fermentação microbiana (y) de 9,5 e 11 g de PB microbiana/MJ energia metabolizável fermentável. Houve diferença para as concentrações de nutrientes digestíveis totais (NDT) e energia metabolizável fermentável (EMFe) ingeridos e para a composição em matéria orgânica e mineral das bactérias ruminais para as dietas ajustadas para diferentes GPC. Houve interação significativa GPC $\times$ y para a ingestão de NDT como porcentagem do peso corporal e a composição em PB e carboidratos totais das bactérias ruminais. Não foram encontradas diferenças para os potenciais de fermentação microbiana. A eficiência de síntese microbiana também não diferiu entre as dietas e apresentou valores de 12,7 g PB microbiana/100 g NDT e 9,2 g PB microbiana/MJ EMFe. As diferenças encontradas não justificaram o balanceamento dos concentrados para os diferentes potenciais de fermentação microbiana avaliados.

Palavras-chave: farelo de algodão, farelo de soja, milho em grão, potencial de ganho de peso, potencial de síntese microbiana, soja em grão

\section{Energy aport, microbial composition and efficiency by bovines fed Brachiaria brizantha cv. Marandu hay and concentrate, balanced for different weight gains and potential of microbial fermentation}

ABSTRACT - The experiment was carried out with the objective to evaluate the energy aport, microbial composition and efficiency of Santa Gertrudis young bulls, canulated in the rumen and duodenum, fed diets with palisadegrass hay and concentrates. A 4 x 4 latin square design was used, in which the treatments were composed by the concentrates adjusted for daily body weight gain (BWG) of 0.5 and $1 \mathrm{~kg} /$ animal and potential microbial fermentation (y) of 9.5 and $11 \mathrm{~g}$ microbial CP/MJ fermentable metabolizable energy. There were differences for the concentrations of total digestible nutrients (TDN) and fermentable metabolizable energy (FMEn) intakes, and for the composition in organic matter and mineral of ruminal bacteria for diets adjusted for different BWG. There was significant BWG x y interaction for TDN intake as percentage of body weight and in the $\mathrm{CP}$ and total carbohydrates composition of the ruminal bacteria. There were no differences for the potential microbial fermentation. The efficiency of microbial synthesis also did not differ among diets and showed values of $12.7 \mathrm{~g}$ microbial CP/100 g TDN and $9.2 \mathrm{~g}$ microbial CP/MJ FMEn. The observed differences did not justify the balancing of the concentrates for the different potential microbial fermentation evaluated.

Key Words: corn grain, cottonseed meal, potential of bodyweight gain, potential of microbial fermentation, soybean grain, soybean meal 


\section{Introdução}

Na avaliação técnico-nutricional do desempenho animal, o suprimento protéico microbiano é um importante alvo de estudos; estimativa deste parâmetro foi incorporada aos sistemas de avaliação de dietas utilizados em diversos centros pecuários do mundo visando controlar as variações na magnitude deste processo simbiótico causadas pela influência de fatores relacionados à dieta basal.

Neste sentido, foram desenvolvidas algumas técnicas para estimar a produção de matéria seca (MS) microbiana por meio de indicadores capazes de caracterizar o microrganismo, entre eles, o ácido diaminopimélico (DAPA), as bases purinas adenina e guanina, descritas por Zinn \& Owens (1986), e os isótopos radioativos, como fósforo e enxofre. Valadares Filho et al. (1990) compararam o método do DAPA e das bases purinas e concluíram que o método das bases purinas foi adequado para estimar a produção microbiana.

Segundo Cecava et al. (1990), na maioria dos trabalhos, utilizou-se uma taxa fixa para $\mathrm{N}$-indicador: $\mathrm{N}$-microbiano de 0,116 na estimativa do fluxo de PBM ao duodeno. Entretanto, fatores que podem alterar o fornecimento de substratos fermentáveis ou a taxa de crescimento microbiano poderiam alterar a composição das células microbianas, além das espécies presentes no rúmen e o tipo de associação de bactérias com frações específicas do conteúdo ruminal. Embora boa parte dessas variações possa ser atribuída às diferentes técnicas utilizadas para isolar e quantificar as bactérias ruminais, Clark et al. (1992) relataram que a composição de bactérias isoladas no rúmen de vacas foi variável quando utilizada a mesma técnica de isolamento e quantificação. Valadares Filho (1995) encontrou composição média das bactérias isoladas, em porcentagem da MS, de $84,6 \%$ de MO, 7,1\% de $\mathrm{N}$ total e 4,6\% de EE.

Nos estudos do aporte de N-microbiano às porções posteriores do sistema digestório, o método dos derivados de purinas (DP) na urina foi considerado muito útil para determinação do potencial simbiótico de dietas fornecidas a ruminantes, pois constituiu um protocolo experimental simples (requer apenas a coleta de urina) e não-invasor (não exige processo cirúrgico no animal como o método das bases purinas). Esse método se baseia no princípio de que os ácidos nucléicos que deixam o rúmen são de origem essencialmente microbiana, exceto em situações em que a dieta contém produtos de origem animal. Os ácidos nucléicos absorvidos são catabolisados e excretados na urina, principalmente na forma de ácido úrico e alantoína no caso da espécie bovina, e estes compostos são determinados pelo método colorimétrico (Chen \& Gomes, 1995).
A absorção de purinas é diretamente relacionada à excreção dos DP na urina, cujo valor permite o cálculo do fluxo de N-microbiano no duodeno, tornando a estimativa melhor se conhecida a taxa $\mathrm{N}$-purinas:N-total das bactérias do rúmen. Funaba et al. (1997) avaliaram o fluxo duodenal de N-microbiano estimado por meio da excreção dos DP em bezerros holandeses recém-desmamados e concluíram que o fluxo de $\mathrm{N}$-microbiano no intestino pode ser estimado por este método, que foi uma boa ferramenta para predizer as mudanças relativas no fluxo duodenal de $\mathrm{N}$-microbiano, em decorrência do regime nutricional ou do desenvolvimento fisiológico do animal.

Objetivou-se com este trabalho avaliar o aporte de energia, a composição de bactérias e a eficiência microbiana em tourinhos Santa Gertrudes alimentados com dietas com feno de capim-marandu e concentrados balanceados para proporcionar dois níveis de ganho de peso, associados a dois potenciais de síntese microbiana. As avaliações foram propostas visando simular animais em regime de semiconfinamento mantidos em pastagem durante a estação seca, recebendo suplementação com concentrado.

\section{Material e Métodos}

O ensaio foi realizado no Setor de Bovinocultura de Corte e no Laboratório de Ruminantes da Faculdade de Ciências Agrárias e Veterinárias - Unesp, em Jaboticabal, SP. A unidade está localizada na região norte do estado de São Paulo, nas coordenadas $21^{\circ} 15^{\prime} 22^{\prime \prime}$ de latitude Sul e $48^{\circ} 18^{\prime} 58^{\prime \prime}$ de longitude Oeste. A altitude local é de 595 m e o clima, segundo classificação de Köppen, é do tipo subtropical, com chuvas de verão e inverno relativamente seco. As médias anuais de precipitação pluviométrica, temperatura e umidade relativa do ar foram calculadas em $1.400 \mathrm{~mm}, 21^{\circ} \mathrm{C}$ e $70 \%$, respectivamente.

A pastagem de capim-marandu (Brachiaria brizantha cv. Marandu ) selecionada para confecção do feno utilizado nas dietas foi mantida sob pastejo durante o período chuvoso e adubada com $130 \mathrm{~kg}$ de N/ha, parcelados em quatro aplicações. Após o período de adubação, seguido de ciclo de pastejo com desfolha de intensidade média, a área foi vedada ao acesso dos animais por aproximadamente 30 dias antes do processo de fenação. Pretendeu-se com esse procedimento simular o pastejo direto durante a estação seca.

Utilizaram-se quatro tourinhos Santa Gertrudes de $380 \mathrm{~kg}$ de peso corporal e 17 meses de idade, canulados no rúmen e no duodeno, segundo técnica descrita por Leão \& Coelho da Silva (1980). Os animais receberam os tratamentos necessários no pré e pós-operatórios para garantia de plena recuperação e, após, foram alojados individual- 
mente em baias de alvenaria de $16 \mathrm{~m}^{2}$, com cocho, bebedouro e saleiro exclusivos.

Foram avaliadas quatro dietas (Tabelas 1 e 2), diferentes quanto à composição dos concentrados, que foram balanceados para proporcionar dois potenciais de fermentação microbiana (y): alto (11 g de PB microbiana/MJ de EM fermentável) e baixo (9,5 g de PB microbiana/MJ de EM fermentável) e fornecidos em quantidade suficiente para ganho diário de peso corporal (GPC) de: 0,5 e 1,0 kg/animal.

Este trabalho fez parte de um conjunto de experimentos (Brito et al., 2006) para estudos de digestibilidade, degradabilidade e desempenho, em que as condições propostas visavam simular a situação de bovinos em pastagem de capim-marandu durante a estação seca e alimentados com concentrado como suplemento, em regime de semiconfinamento.

O período experimental teve duração de 64 dias, subdivididos em quatro períodos de 16 dias, os sete primeiros de adaptação à dieta. As bases do protocolo experimental seguiram as indicações de Fu et al. (2001) e Ítavo et al. (2002a). Durante todo o período experimental, os animais foram alimentados ad libitum com feno, parcelado em duas refeições diárias (7 e 17h). O concentrado foi fornecido apenas na primeira refeição do dia, de acordo com cada dieta. Os animais foram pesados no início do período experimental e no final de cada subperíodo.

Todos os dias pela manhã as sobras de alimento nos cochos foram quantificadas e amostradas de forma representativa para controle da quantidade de alimento consumida pelos animais.

A digestão dos nutrientes foi estimada utilizando-se a fibra em detergente ácido indigestível (FDAi) como indicador interno (Penning \& Jonhson, 1983). Os procedimentos para a estimativa da digestão total e parcial das frações nutritivas das rações seguiram as recomendações de Sampaio et al. (2000) e Berchielli et al. (2000), com as modificações propostas por Ítavo et al. (2002b).

A digesta duodenal foi coletada via cânula e as fezes diretamente do piso, às $10 \mathrm{~h}$ no primeiro dia e às $16 \mathrm{~h}$ no segundo dia de coleta. A coleta de fezes do piso foi adotada

Tabela 1 - Composição bromatológica dos ingredientes utilizados

Table 1 - Chemical composition of the used ingredients

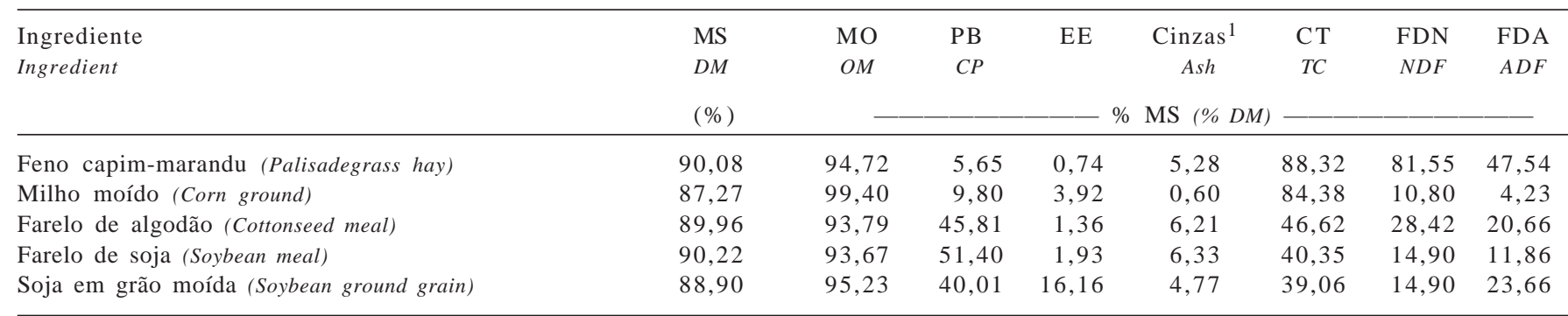

Tabela 2 - Composição percentual dos ingredientes e características das dietas

Table 2 - Percentage composition of ingredients and diet characteristics

\begin{tabular}{|c|c|c|c|c|}
\hline \multirow[t]{2}{*}{$\begin{array}{l}\text { Ingrediente (\%) } \\
\text { Ingredient }\end{array}$} & \multicolumn{2}{|c|}{$\begin{array}{c}\text { Baixo } \mathrm{GPC}^{1} \\
\text { Low } B W G\end{array}$} & \multicolumn{2}{|c|}{$\begin{array}{l}\text { Alto } \mathrm{GPC}^{1} \\
\text { High } B W G\end{array}$} \\
\hline & $\begin{array}{c}\text { Baixo } \mathrm{y}^{2} \\
\text { Low } y^{2}\end{array}$ & $\begin{array}{l}\text { Alto } y^{2} \\
\text { High } y^{2}\end{array}$ & $\begin{array}{c}\text { Baixo } \mathrm{y}^{2} \\
\text { Low } y^{2}\end{array}$ & $\begin{array}{l}\text { Alto } \mathrm{y}^{2} \\
\text { High } y^{2}\end{array}$ \\
\hline Milho moído (Corn ground) & 47,4 & 33,3 & 50,8 & 27,8 \\
\hline Farelo de algodão (Cottonseed meal) & 20,7 & 20,7 & 13,1 & 13,1 \\
\hline Farelo de soja (Soybean meal) & 5,8 & 19,9 & 19,6 & 42,6 \\
\hline Soja em grão moído (Soybean ground grain) & 22,8 & 22,8 & 14,4 & 14,4 \\
\hline Mistura mineral ${ }^{3}$ (Mineral mix) & 3,3 & 3,3 & 2,1 & 2,1 \\
\hline \multicolumn{5}{|l|}{$\begin{array}{l}\text { Característica das dietas } \\
\text { Diet characteristics }\end{array}$} \\
\hline PB (\% MS) $(C P, \% \quad D M)$ & 11,8 & 13,6 & 14,3 & 15,2 \\
\hline EM (MJ/kg MS) (ME, MJ/kg DM) & 9,4 & 9,4 & 10,1 & 10,0 \\
\hline Ingestão de MS (DM intake) (kg/anim.d) & 7,03 & 7,08 & 8,10 & 8,03 \\
\hline Relação volumoso:concentrado (Forage:concentrate ratio) & 69:31 & $70: 30$ & $58: 42$ & $58: 42$ \\
\hline
\end{tabular}


por reduzir o estresse causado em alguns animais pela coleta do reto. Esse procedimento não trouxe prejuízo à qualidade e ao horário da coleta, visto que o piso foi lavado com água nos dias de coleta e os animais defecavam em quantidade suficiente assim que se efetuava sua contenção por meio de cabrestos.

As amostras foram acondicionadas em sacos plásticos e mantidas em congelador, devidamente identificadas. Ao final do período, cada amostra de digesta e de fezes foi liofilizada, moída e analisada quanto ao teor de FDAi, após a formação de amostras compostas por animal e por período. A FDAi foi obtida após 144 horas de incubação do material no rúmen (Penning \& Jonhson, 1983). Parte desse material, juntamente com as amostras de alimento e de sobras, também foi encaminhada ao laboratório para análise de MS, PB, cinzas, EE e carboidratos totais (CT), segundo AOAC (1995); além da FDN e FDA, conforme Van Soest \& Wine (1998). $\mathrm{O}$ teor de MO foi estimado pela diferença entre o teor de cinzas e os carboidratos totais, conforme descrito por Sniffen et al. (1992), a fim de possibilitar a determinação da ingestão, do fluxo e da excreção de nutrientes pelo animal.

Após a coleta de fezes e de digesta duodenal, foram coletadas amostras de 1,5 L de líquido ruminal, que foram diluídas em 0,5 L de solução salina para posterior isolamento de bactérias ruminais por centrifugação diferenciada (Cecava et al., 1990), realizada em centrífuga refrigerada, em seguida o material foi liofilizado e determinados os teores de MS, MO, PB, EE e cinzas e da relação Npurina:Ntotal (Zinn \& Owens, 1986) destas bactérias para o cálculo do fluxo de proteína microbiana no duodeno. As amostras de digesta coletadas no duodeno foram desidratadas em liofilizador e analisadas quanto ao $\mathrm{N}$-microbiano por meio da relação Npurina:Ntotal das bactérias isoladas do rúmen.

No último dia do período experimental, a urina excretada foi coletada durante 12 horas em reservatório contendo $50 \mathrm{~mL}$ de solução de $\mathrm{H}_{2} \mathrm{SO}_{4}$ a $10 \%$ para manter o $\mathrm{pH}$ do material abaixo de 3. Parte da urina coletada foi diluída quatro vezes e armazenada a $-20^{\circ} \mathrm{C}$. Posteriormente, este material foi descongelado e submetido a análises de alantoína e ácido úrico (Rennó et al., 2000). A alantoína foi hidrolisada em condições fracamente alcalinas a ácido alantóico e depois a uréia e ácido glioxílico em solução levemente ácida. O ácido glioxílico reagiu com a fenilhidrazina hidroclórica para produzir a fenilhidrazona, a qual reagiu com potássio para formar um composto que foi quantificado a $522 \mathrm{~nm}$ em espectrofotômetro. O ácido úrico das amostras foi tratado com uricase e convertido em alantoína. Após o tratamento, a densidade óptica da amostra foi nula. A variação na densidade óptica entre a amostra tratada e não-tratada indicou a concentração da mólecula-problema, por meio de curvas-padrão pré-estabelecidas. A partir dos dados de excreção de alantoína e ácido úrico e da composição das bactérias em cada ração, foi estimado o fluxo de $\mathrm{N}$-microbiano no intestino proporcionado pelas diferentes dietas, conforme descrito a seguir:

Total de purinas microbianas absorvidas $(\mathrm{mmol} / \mathrm{dia})=$

$$
\left(\mathrm{Y}-0,385 \times \mathrm{PC}^{0,75}\right) / 0,85
$$

Fluxo de $\mathrm{N}$-microbiano $(\mathrm{g} / \mathrm{dia})=(\mathrm{A} \times 70) \div(0,116 \times 0,83 \times$ 1000)

em que $\mathrm{A}=$ total de purinas microbianas absorvidas, Y = quantidade de ácido úrico e alantoína excretados (mmol/ dia), e PC = peso corporal (Chen \& Gomes, 1995).

As médias foram estudadas em esquema de quadrado latino $4 \times 4$ (animais $\times$ períodos) com quatro tratamentos no modelo fatorial $2 \times 2($ GPC $\times$ y). Foi realizada análise de variância por meio do teste $\mathrm{F}$ a $5 \%$ de probabilidade (Sampaio, 1998).

\section{Resultados e Discussão}

Com base nos dados de digestão das diferentes frações, foram calculados o aporte energético, a concentração energética e as frações aproveitadas no rúmen (Tabela 3).

Quando considerados os diferentes potenciais de ganho de peso corporal (GPC), observou-se que, em virtude do planejamento experimental na escolha das dietas, houve maior $(\mathrm{P}<0,05)$ aporte energético nos animais sob regime de maior GPC. Apesar de previsto, como não foram observadas diferenças $(\mathrm{P}>0,05)$ no aproveitamento da $\mathrm{MO}$ e dos carboidratos totais, frações diretamente relacionadas à energia da dieta, esse resultado indicou que ambos os níveis de GPC foram beneficiados de modo semelhante pela fração energética das dietas enquanto esta fração esteve no rúmen.

Não houve qualquer diferença $(\mathrm{P}>0,05)$ entre as dietas ajustadas para diferentes potenciais de fermentação microbiana. Em situação específica, foi verificada interação entre as dietas quanto à ingestão relativa de energia, expressa em relação ao peso corporal (PC) (Tabela 4). Ao analisar o potencial de fermentação, observou-se maior $(\mathrm{P}<0,05)$ ingestão relativa de NDT pelos animais sob maior GPC. No entanto, quando os animais foram alimentados com a dieta para baixo GPC, a ingestão de NDT foi maior $(\mathrm{P}<0,05)$ no caso de alto potencial de fermentação.

Véras et al. (2000) avaliaram o fornecimento de concentrado nos níveis 25 e 75\% da MS de dietas à base de feno de Brachiaria decumbens + feno de coastcross para tourinhos Nelore de $330 \mathrm{~kg}$. O consumo diário de NDT foi de 4,96 e 5,70 kg/animal, respectivamente, para 30 e 42,5\% de MS de concentrado na dieta. 
Tabela 3 - Ingestão diária de energia, concentração energética da dieta e aproveitamento de frações no rúmen por tourinhos Santa Gertrudes alimentados com feno de capim-marandu e concentrado para diferentes potenciais de produção e fermentação

Table 3 - Daily energy intake, diet energy concentration and utilization of fractions in the rumen by Santa Gertrudis young bulls fed palisadegrass hay and concentrate for different fermentation and production potentials

\begin{tabular}{|c|c|c|c|c|c|c|c|}
\hline \multirow[t]{2}{*}{ Item } & \multicolumn{2}{|c|}{$\begin{array}{l}\mathrm{GPC}^{1} \\
B W G^{1}\end{array}$} & \multicolumn{3}{|c|}{$y^{2}$} & \multirow[b]{2}{*}{ F } & \multirow[t]{2}{*}{ CV (\%) } \\
\hline & $\begin{array}{c}\text { Baixo } \\
\text { Low }\end{array}$ & $\begin{array}{l}\text { Alto } \\
\text { High }\end{array}$ & $\mathrm{F}$ & $\begin{array}{c}\text { Baixo } \\
\text { Low }\end{array}$ & $\begin{array}{l}\text { Alto } \\
\text { High }\end{array}$ & & \\
\hline MS ingerida (kg/animal) (Intaked DM) & 7,05 & 8,07 & $*$ & 7,57 & 7,56 & ns & 2,81 \\
\hline Relação volumoso:concentrado (Forage:concentrate ratio) & $70: 30$ & $57: 43$ & & $63: 37$ & $63: 37$ & & \\
\hline NDT ingerido (kg/animal) (Intaked NDT) & 3,87 & 4,88 & $*$ & 4,37 & 4,38 & ns & 4,20 \\
\hline Concentração energética (MJ/kg MS) (Energetic concentration) & 8,28 & 9,14 & * & 8,68 & 8,75 & ns & 3,56 \\
\hline EMFe ingerida (MJ/animal) (Intaked FeME, MJ/animal) & 52,98 & 68,02 & $*$ & 60,24 & 60,75 & ns & 4,54 \\
\hline MO digerida no rúmen (kg/dia) (OM rumen digested) & 3,80 & 4,33 & ns & 3,99 & 4,13 & ns & 16,25 \\
\hline CT digeridos no rúmen (kg/dia) (TC rumen digested) & 2,69 & 2,85 & ns & 2,79 & 2,74 & ns & 23,53 \\
\hline
\end{tabular}

ns - não-significativo; * $(P<0,05)$, teste $F$.

${ }^{1} \mathrm{GPC}$ - ganho diário estimado de peso corporal: alto (1 kg/animal) e baixo $(0,5 \mathrm{~kg} / \mathrm{animal})$.

${ }^{2}$ y - potencial estimado de fermentação microbiana: alto (11 g PB microbiana/MJ EM fermentável) e baixo (9,5 g PB microbiana /MJ EM fermentável).

${ }^{3}$ EMFe - energia metabolizável fermentável, CT - carboidratos totais.

ns - not significant; * $(P<0.05)$, F test,

${ }^{1}$ BWG - estimated daily body weight gain: high (1 kg/animal) and low $(0.5 \mathrm{~kg} / \mathrm{animal})$.

${ }^{2}$ Estimated potential of microbial fermentation: high (11 g of microbial CP/MJ of fermentable ME) and low (9.5 g of microbial CP/MJ of fermentable ME).

${ }^{3}$ FeME-fermentable metabolizable energy, TC-total carbohydrates.

Tabela 4 - Ingestão diária relativa de nutrientes digestíveis totais (\% PC) por tourinhos Santa Gertrudes alimentados com feno de capim-marandu e concentrado para diferentes potenciais de produção e fermentação

Table 4 - Relative total digestible nutrient intake (\% BW) by Santa Gertrudis young bulls fed hay of palisadegrass and concentrate for different fermentation and production potentials

\begin{tabular}{lllc}
\hline GPC $^{1}$ & \multicolumn{2}{c}{$\mathrm{y}^{2}$} & \multirow{2}{*}{$\begin{array}{c}\text { Média } \\
\text { M } W G\end{array}$} \\
\cline { 2 - 3 } & $\begin{array}{c}\text { Baixo } \\
\text { Low }\end{array}$ & $\begin{array}{c}\text { Alto } \\
\text { High }\end{array}$ & \\
\hline Baixo (Low) & $0,92 \mathrm{Bb}$ & $0,98 \mathrm{Ba}$ & 0,95 \\
Alto (High) & $1,24 \mathrm{Aa}$ & $1,18 \mathrm{Aa}$ & 1,21 \\
Média (Mean) & 1,08 & 1,08 & - \\
\hline
\end{tabular}

Médias seguidas de letras distintas, minúsculas (linha) e maiúscula (coluna), diferem $(P<0,05)$ pelo teste $F$.

${ }^{1}$ GPC - Ganho diário estimado de peso corporal: alto (1 kg/animal) e baixo $(0,5 \mathrm{~kg} /$ animal $)$.

2 y - Potencial estimado de fermentação microbiana: alto (11 g PB microbiana/MJ EM fermentável); e baixo (9,5 g PB microbiana/MJ de EM fermentável).

Means followed by different letters, small (row) and capital (column), are different $(P<0.05)$ by F test.

${ }^{1}$ BWG - Estimated daily body weight gain: high (1 kg/animal) and low (0.5 kg/animal).

${ }^{2}$ Estimated potential of microbial fermentation: high (11 g microbial CP/MJ fermentable ME); and low (9.5 g microbial CP/MJ fermentable ME).

Lançanova et al. (2001) avaliaram o efeito de cinco grupos genéticos (Gir, Nelore, Guzerá, Caracu e Santa Gertrudes) e verificaram semelhança na concentração energética da dieta ingerida pelos animais, com médias de $52 \%$ de NDT em rações à base de feno de Brachiaria brizantha, milho e farelo de algodão, utilizando métodos de coleta total e lignina em detergente ácido. As médias observadas neste ensaio para o mesmo volumoso foram de 54,9 e 60,5\% de NDT para baixo e alto GPC, respectivamente, superior à obtida por esses autores (Brito et al., 2006).

Para estudar algumas características na dinâmica da biomassa microbiana no rúmen, é preciso considerar inicialmente a composição e as propriedades características das bactérias ruminais isoladas do líquido ruminal dos animais alimentados com cada uma das dietas. Neste estudo, não houve diferença $(\mathrm{P}>0,05)$ na composição de bases purinas e da fração lipídica em qualquer dos fatores analisados, GPC ou fermentação (médias de 13,32 e 3,92\% na MS, respectivamente) (Tabela 5). No entanto, sob menor GPC, as bactérias apresentaram maior concentração de minerais e menor teor de MO.

A composição em PB e CT das bactérias que apresentaram comportamento de interação das dietas avaliadas está apresentada na Tabela 6. Sob condições de baixo potencial fermentativo, a elevação do nível de produção resultou em maior $(\mathrm{P}<0,05)$ teor protéico nas bactérias. Sob baixo potencial de fermentação, as bactérias apresentaram menor $(\mathrm{P}<0,05)$ teor de CT em alto ganho de peso. Os coeficientes de variação foram 4,00 e 3,24\%, respectivamente, para a composição em PB e carboidratos totais.

Considerando que o protocolo de isolamento foi eficiente, o resultado foi de difícil compreensão, uma vez que Craig et al. (1987) relataram diferenças no teor de $\mathrm{N}$ de bactérias isoladas do rúmen em diferentes tempos pósalimentação. Neste trabalho, a amostragem foi sempre no mesmo horário, pois, como relatado por esses autores, essa prática eliminaria a variabilidade na composição de bactérias. 
Tabela 5 - Composição em MO, EE, cinzas e bases purinas de bactérias isoladas do líquido ruminal de tourinhos Santa Gertrudes alimentados com feno de capimmarandu e concentrado para diferentes potenciais de produção e fermentação

Table 5 - Composition in OM, EE, ash and purine bases of isolated bacterias of ruminal liquid by Santa Gertrudis young bulls fed hay of palisadegrass and concentrate for different fermentation and production potentials

\begin{tabular}{|c|c|c|c|c|c|c|c|}
\hline \multirow[t]{2}{*}{ Item } & \multicolumn{2}{|c|}{$\begin{array}{l}\mathrm{GPC}^{1} \\
B W G\end{array}$} & \multirow[b]{2}{*}{$\mathrm{F}$} & \multicolumn{2}{|c|}{$y^{2}$} & \multirow[b]{2}{*}{$\mathrm{F}$} & \multirow[t]{2}{*}{ CV (\%) } \\
\hline & $\begin{array}{l}\text { Baixo } \\
\text { Low }\end{array}$ & $\begin{array}{r}\text { Alto } \\
\text { High }\end{array}$ & & $\begin{array}{l}\text { Baixo } \\
\text { Low }\end{array}$ & $\begin{array}{l}\text { Alto } \\
\text { High }\end{array}$ & & \\
\hline MO $(O M)^{3}$ & 91,47 & 92,65 & $*$ & 92,03 & 92,10 & ns & 0,80 \\
\hline $\mathrm{EE}^{3}$ & 4,04 & 3,81 & ns & 4,20 & 3,65 & ns & 18,50 \\
\hline Cinzas $(\text { Ash })^{3}$ & 8,52 & 7,34 & $*$ & 7,97 & 7,89 & ns & 9,28 \\
\hline $\begin{array}{l}\text { RNApurina }{ }^{3} \\
\text { ARN purine }\end{array}$ & 12,57 & 14,08 & ns & 12,49 & 14,17 & ns & 14,09 \\
\hline
\end{tabular}

ns - não-significativo; * $(P<0,05)$, teste $F$.

${ }^{1}$ GPC - Ganho diário estimado de peso corporal: alto (1 kg/ animal) e baixo (0,5 kg/animal).

2 y - potencial estimado de fermentação microbiana: alto (11 g PB microbiana/MJ EM fermentável) e baixo (9,5 g PB microbiana/MJ EM fermentável).

3 Porcentagem da MS

ns - no significant; * $(P<0.05)$, F test.

1 BWG - Estimated daily body weight gain: high (1 kg/animal) and low $(0.5 \mathrm{~kg} / \mathrm{animal})$.

${ }^{2}$ Estimated potential of microbial fermentation: high (11 g microbial CP/MJ fermentable ME) and low (9.5 g microbial CP/MJ fermentable ME).

${ }^{3}$ Percent of $D M$

A suposição de que as bactérias do rúmen, em virtude da variação nos nutrientes da dieta, alterariam a taxa de armazenagem de $\mathrm{N}$ e CT no interior de suas células, que explicaria esse resultado, merece maiores investigações. O trabalho de Russel (1998) apontou nesta direção.

Cecava et al. (1990) e Clark et al. (1992) sumarizaram dados de mais de 50 trabalhos e observaram que as diferenças na composição da MS bacteriana foram pronunciadas e apresentaram valores de 60,8 a 92,2\% para MO, de 30 a 66,25\% para PB e de 0,61 a 2,13 para relação Npurina:Ntotal. Os dados obtidos neste estudo foram compatíveis com as faixas de valores citadas por esses autores.

Bürguer et al. (2000) obtiveram médias de 92,59; 51,56 e 9,67\% da MS para MO, PB e EE bacterianos, respectivamente. Dias et al. (2000) obtiveram médias de 93,13; 53,31; 29,27 e 10,52\% da MS para MO, PB, CT e EE bacterianos, respectivamente, em novilhos F1 Limousin-Nelore de 286 kg alimentados com feno de coast-cross e milho e farelo de soja como suplemento. Tibo et al. (2000) verificaram médias de 89,12; 39,90; 36,30 e 10,51\% da MS para MO, PB, CT eEE bacterianos, respectivamente, em novilhos F1 Simental-Nelore nãocastrados de $300 \mathrm{~kg}$ alimentados com feno de coast-cross e suplemento à base de milho e farelo de soja, em níveis de 25 a 75\% MS da dieta. Cardoso et al. (2000) obtiveram médias de 91,07; 54,50; 29,85 e 6,74\% da MS para MO, PB, CT e EE de bactérias do rúmen de novilhos F1 Limousin-Nelore.
Tabela 6 - Composição em proteína bruta e carboidratos totais de bactérias isoladas do líquido ruminal por tourinhos Santa Gertrudes alimentados com feno de capimmarandu e concentrado para diferentes potenciais de produção e fermentação

Table 6 - Composition in CP and TC of isolated bacterias of ruminal liquid by Santa Gertrudis young bulls fed palisadegrass hay and concentrate for different fermentation and production potentials

\begin{tabular}{|c|c|c|c|}
\hline \multirow{2}{*}{$\begin{array}{l}\mathrm{GPC}^{1} \\
B W G\end{array}$} & \multicolumn{2}{|c|}{$y^{2}$} & \multirow{2}{*}{$\begin{array}{l}\text { Média } \\
\text { Mean }\end{array}$} \\
\hline & $\begin{array}{c}\text { Baixo } \\
\text { Low }\end{array}$ & $\begin{array}{r}\text { Alto } \\
\text { High }\end{array}$ & \\
\hline \multicolumn{4}{|c|}{$\mathrm{PB}(\% \mathrm{MS})(C P, \% D M)$} \\
\hline Baixo (Low) & $45,46 \mathrm{Bb}$ & 48,93Аа & 47,19 \\
\hline Alto (High) & $50,91 \mathrm{Aa}$ & 48,79 Аа & 49,85 \\
\hline Média (Mean) & 48,18 & 48,86 & - \\
\hline \multicolumn{4}{|c|}{ CT (\% MS) (TC, \% DM) } \\
\hline Baixo (Low) & $41,37 \mathrm{Aa}$ & $39,11 \mathrm{Ab}$ & 40,24 \\
\hline Alto (High) & $37,91 \mathrm{Ba}$ & $40,08 \mathrm{Aa}$ & 38,99 \\
\hline Média (Mean) & 39,64 & 39,60 & - \\
\hline
\end{tabular}

Médias seguidas de letras distintas, minúsculas (linha) e maiúscula (coluna), diferem $(P<0,05)$ pelo teste $F$.

${ }^{1} \mathrm{GPC}$ - ganho diário estimado de peso corporal: alto (1 kg/animal) e baixo $(0,5 \mathrm{~kg} / \mathrm{animal})$.

2 y - potencial estimado de fermentação microbiana: alto (11 g PB microbiana/MJ de EM fermentável) e baixo (9,5 g PB microbiana/MJ EM fermentável).

Means followed by different letters, small (row) and capital (column), are different $(P<0.05)$ by F test.

${ }^{1}$ BWG - estimated daily body weight gain: high (1 $\mathrm{kg} /$ animal) and low (0.5 kg/animal).

2 Estimated potential of microbial fermentation: high (11 g microbial CP/MJ fermentable ME) and low (9.5 g microbial CP/MJ fermentable ME).

Não foi observada diferença $(\mathrm{P}>0,05)$ entre as dietas avaliadas na excreção diária de urina, expressa em diferentes unidades (Tabela 7).

Os níveis de excreção urinária foram próximos do limite inferior, mas dentro da faixa indicada por Church (1988), de 17 a 45 mL/kg de PC. Esse autor relatou que diversos fatores podem contribuir para a variação deste índice, entre eles, o consumo de água e sal, a natureza da dieta, a atividade física e a temperatura ambiente. No entanto, nenhum desses fatores parece ter contribuído para produzir diferenças significativas nas médias obtidas em cada dieta neste estudo.

A excreção de derivados de purina (DP) diferiu entre as dietas para diferentes níveis de GPC; as maiores médias $(\mathrm{P}<0,05)$ de excreção de alantoína e ácido úrico foram obtidas nos animais alimentados com o concentrado para alto GPC. Church (1988) relatou que a urina é a principal rota de excreção para a maioria dos produtos residuais originados do metabolismo corporal de compostos nitrogenados. Além disso, enquanto a ingestão de $\mathrm{N}$ limita o aporte de microrganismos ao intestino delgado, a quantidade de alantoína excretada está positivamente correlacionada ao consumo 
Tabela 7 - Excreção de urina e derivados de purinas por tourinhos Santa Gertrudes alimentados com feno de capim-marandu e concentrado para diferentes potenciais de produção e fermentação

Table 7 - Urine excretion and purine derivates by Santa Gertrudis young bulls fed palisadegrass hay and concentrate for different fermentation and production potentials

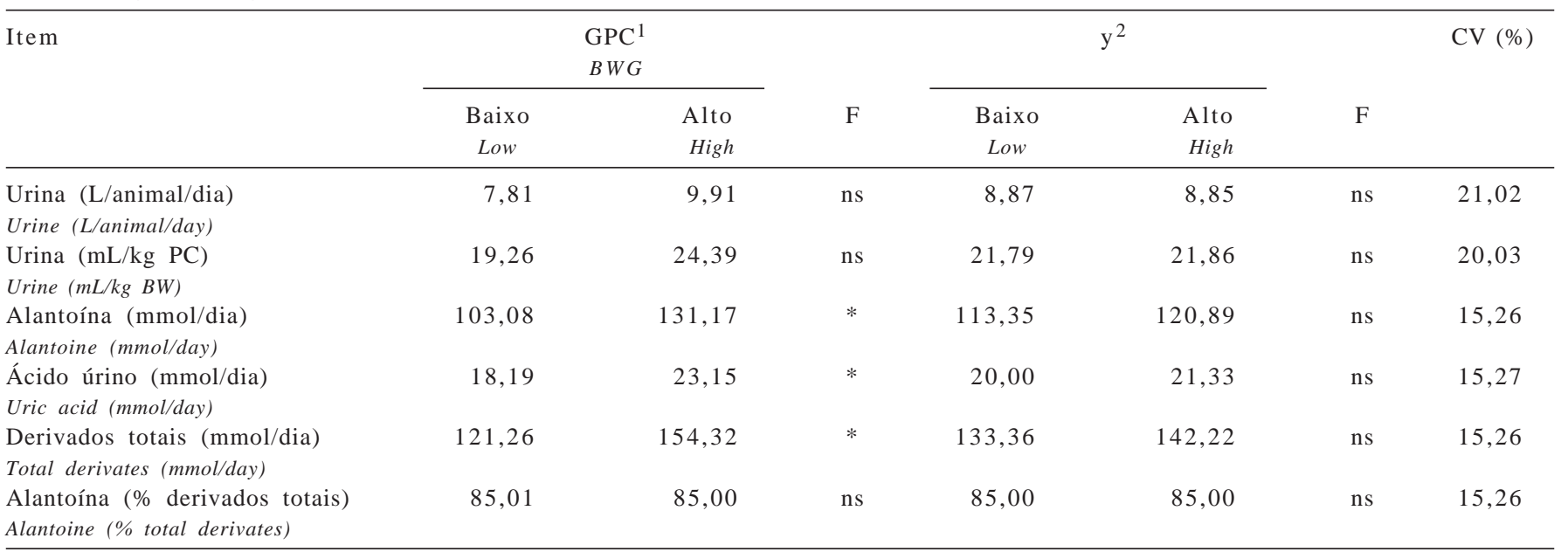

ns - não-significativo; * $(P<0,05)$, teste $F$.

${ }^{1}$ GPC - ganho diário estimado de peso corporal: alto $(1 \mathrm{~kg} / \mathrm{animal})$ e baixo $(0,5 \mathrm{~kg} / \mathrm{animal})$.

2 y - potencial estimado de fermentação microbiana: alto (11 g PB microbiana/MJ de EM fermentável) e baixo (9,5 g PB microbiana/MJ EM fermentável). ns - no significant; * $(P<0.05)$, F test.

1 BWG - estimated daily body weight gain: high (1 kg/animal) and low $(0.5 \mathrm{~kg} / \mathrm{animal})$.

2 Estimated potential of microbial fermentation: high (11 g microbial CP/MJ fermentable ME) and low (9.5 g microbial CP/MJ fermentable ME).

de $\mathrm{N}$ digestível. É possível que os resultados de digestão da PB obtidos (Brito et al., 2006), tenham contribuído para as diferenças obtidas para DP entre os concentrados para GPC. Entre os potenciais de fermentação, não foram verificadas diferenças $(P>0,05)$ na excreção de $D P$ na urina.

Em compilação de diversos resultados obtidos utilizando-se os DP para estimativa do fluxo microbiano, Rennó et al. (2000) verificaram que, em animais mestiços, a excreção de alantoína foi de 80 e $87 \mathrm{mmol} /$ dia, respectivamente, para 30,0 e $42,5 \%$ de concentrado na dieta. Nos trabalhos avaliados, a excreção de ácido úrico foi sempre de $7,86 \mathrm{mmol} / \mathrm{dia}$. Ambos os valores são menores que os obtidos neste trabalho. De qualquer modo, a soma de alantoína e do ácido úrico excretados manteve-se constante quando apresentado como proporção dos derivados totais, em torno de $98 \%$, independentemente do nível de concentrado utilizado. Nesta pesquisa, a proporção de alantoína em relação aos derivados totais também se manteve constante em todas as dietas (Tabela 7) e o valor (85\%) foi similar aos encontrados por Verbic et al. (1990) e Vagnoni et al. (1997), entre 84 e $87 \%$, para qualquer das taxas de infusão de purina no abomaso avaliadas.

As unidades de eficiência de síntese de proteína microbiana foram calculadas considerando as estimativas das frações digeridas no rúmen obtidas neste estudo (Tabela 8). Para cálculo da ingestão de EMFe, descontou-se a energia da fração EE ingerida, de $35 \mathrm{MJ} / \mathrm{kg}$ de MS, visto que os animais não ingeriram qualquer alimento pré- fermentado. Não houve diferença $(\mathrm{P}>0,05)$ entre as variáveis estudadas, à exceção do fluxo de $\mathrm{N}$ microbiano no duodeno nos diferentes níveis de GPC, justificado pela maior ingestão de NDT pelos animais alimentados com o concentrado para alto GPC (Tabela 3), determinando conseqüentemente maior fermentação (Tabela 7) e maior fluxo desta fração para o trato inferior.

Os resultados obtidos neste estudo para o fluxo de $\mathrm{N}$-microbiano no abomaso nos animais alimentados com concentrado para baixo GPC foram similares aos descritos por Rennó et al. (2000) para animais mestiços, de 67,27 e 82,05 g/dia para 30 e $42,5 \%$ de concentrado na dieta. Segundo esses autores, a média geral de fluxo de $\mathrm{N}$ microbiano pelo método de DP para animais mestiços foi de $82 \mathrm{~g} / \mathrm{dia}$.

Os valores de eficiência de síntese microbiana encontrados foram coerentes aos referenciais dos sistemas de nutrição de ruminantes, embora esses referenciais nem sempre tenham sido próximos. A produção microbiana tem sido expressa de diferentes formas: o ARC (1984) apresentou o valor médio de $32 \mathrm{~g} \mathrm{~N}$ microbiano/kg de MOADR para eficiência microbiana, ao passo que o AFRC (1993) expressou essa eficiência em gramas de PBM produzida por unidade deEMFe(9, 10 e 11). O NRC (1996) recomendou o valor $130 \mathrm{~g}$ de $\mathrm{PBM} / \mathrm{kg}$ de NDT ingerido, em dietas contendo mais de $40 \%$ de volumoso. O CNCPS (Fox et al., 1992) utilizou o valor médio de $400 \mathrm{~g}$ de MS bacteriana/kg de CHOADR e o sistema PDI estabeleceu a produção microbiana em 145 g 
Tabela 8 - Fluxo de nitrogênio (N) microbiano e eficiência de síntese microbiana em tourinhos Santa Gertrudes alimentados com feno de capim-marandu e concentrado para diferentes potenciais de produção e fermentação

Table 8 - $\quad$ Nitrogen (N) flux and microbial synthesis efficiency by Santa Gertrudis young bulls fed palisadegrass hay and concentrate for different fermentation and production potentials

\begin{tabular}{|c|c|c|c|c|c|c|c|}
\hline \multirow[t]{2}{*}{ Item } & \multicolumn{2}{|c|}{$\begin{array}{c}\mathrm{GPC}^{1} \\
B W G\end{array}$} & \multicolumn{3}{|c|}{$y^{2}$} & \multirow[b]{2}{*}{$\mathrm{F}$} & \multirow[t]{2}{*}{ CV (\%) } \\
\hline & $\begin{array}{l}\text { Baixo } \\
\text { Low }\end{array}$ & $\begin{array}{r}\text { Alto } \\
\text { High }\end{array}$ & F & $\begin{array}{l}\text { Baixo } \\
\text { Low }\end{array}$ & $\begin{array}{l}\text { Alto } \\
\text { High }\end{array}$ & & \\
\hline $\begin{array}{l}\mathrm{N} \text { microbiano no duodeno (g/dia) } \\
\text { Microbial } N \text { in duodenum (g/day) }\end{array}$ & 73,8 & 102,3 & $*$ & 84,2 & 91,9 & ns & 20,3 \\
\hline $\begin{array}{l}\mathrm{N} \text { microbiano/MOADR }(\mathrm{g} / \mathrm{kg}) \\
\text { Microbial N/RADOM }\end{array}$ & 21,3 & 26,4 & ns & 21,9 & 25,7 & ns & 24,8 \\
\hline $\begin{array}{l}\text { MS microbiana/CHOADR (g/kg) } \\
\text { Microbial DM/RADTCHO }\end{array}$ & 424,4 & 883,6 & ns & 420,0 & 888,1 & ns & 121,3 \\
\hline $\begin{array}{l}\text { PB microbiana/EMFe (g/MJ) } \\
\text { Microbial CP/FeME }\end{array}$ & 9,0 & 9,4 & ns & 8,9 & 9,6 & ns & 21,4 \\
\hline
\end{tabular}

ns - não-significativo; * $(\mathrm{P}<0,05)$, teste $\mathrm{F}$.

1 GPC - ganho diário estimado de peso corporal: alto (1 kg/animal) e baixo $(0,5 \mathrm{~kg} / \mathrm{animal}){ }^{2}$ y - potencial estimado de fermentação microbiana: alto

(11 g PB microbiana/MJ de EM fermentável) e baixo (9,5 g PB microbiana /MJ EM fermentável).

ns - no significant; * $(P<0.05)$, F test.

${ }^{1}$ BWG - estimated daily body weight gain: high (1 kg/animal) and low (0.5 kg/animal).

${ }^{2}$ Estimated potential of microbial fermentation: high (11 g microbial CP/MJ fermentable ME) and low (9.5 g microbial CP/MJ fermentable ME).

de PBM/kg de MOF (Jarrige, 1990). Neste último caso, o valor estimado neste ensaio foi de 149,06 g PBM/kg de MOF, próximo ao preconizado por Jarrige (1990).

Bürguer et al. (2000) avaliaram níveis de concentrado na MS da dieta (30, 45, 60, 75 e 90\%) para novilhos alimentados com feno de coastcross, farelo de soja e milho e obtiveram eficiências de síntese microbiana de 383,8 e 448,42 g de $\mathrm{MS} / \mathrm{kg}$ de CHOADR para 30 e $45 \%$ de concentrado na dieta. Nesses níveis de concentrado, os autores encontraram 35,09 e 39,86 g de N-microbiano/kg de MOADR, respectivamente. Dias et al. (2000) obtiveram médias de 35,17 g $\mathrm{N}$-microbiano/kg MOADR e 355,66 g MS microbiana/kg CHOADR em novilhos F1 Limousin-Nelore de 286 kg alimentados com dietas à base de feno de coast-cross e diferentes proporções de concentrado (25 a 75\% MS), no entanto, verificaram eficiências de síntese de 16,90 e 15,65 g/100 g NDT para 30 e 42,5\% MS da dieta como concentrado suplementar, respectivamente. A eficiência de síntese obtida neste estudo no tratamento baixo GPC foi próxima à encontrada por Tibo et al. (2000), de 446,6 g MS bacteriana/kg CHOADR com $30 \%$ da MS de concentrado em dieta à base de feno de Brachiaria decumbens + coastcross, assim como a produção de 12,37 g PB microbiana/100 g NDT.

Cardoso et al. (2000) verificaram médias de 41,70 g $\mathrm{N}$-microbiano/kg MOADR; 41,09 g N-microbiano/kg CHOADR; 472,44 g MS microbiana/kg CHOADR e 16,02 g PBM/100 g NDT em novilhos F1 Limousin-Nelore alimentados com dietas à base de feno coast-cross suplementadas com 25 e $75 \%$ MS de concentrado.

\section{Conclusões}

Apesar das diferenças quanto ao aporte de energia e à composição dos microrganismos do rúmen quando fornecidos concentrados para diferentes potenciais de ganho de peso corporal, não houve alteração da eficiência de síntese microbiana.

O fornecimento de concentrado visando alterar a eficiência de síntese microbiana foi ineficaz nos potenciais de 9,5 e 11 g de proteína bruta microbiana/MJ de energia metabolizável fermentável. Portanto, não se justifica o aumento do custo do quilograma de concentrado para o nível mais alto de potencial de fermentação microbiana.

\section{Literatura Citada}

AGRICULTURAL AND FOOD RESEARCH COUNCIL - AFRC. Energy and protein requirements of ruminants. Wallingford: CAB International, 1993. 159p.

AGRICULTURAL RESEARCH COUNCIL - ARC. The nutrient requirements of ruminant livestock. Farnham Royal, 1984. 45p. (suppl. 1).

ASSOCIATION OF OFFICIAL ANALYTICAL CHEMISTS - AOAC. Official methods of analysis. 16.ed. Washington, 1995. v.1, p.1-30.

BERCHIELLI, T.T.; ANDRADE, P.; FURLAN, C.L. Avaliação de indicadores internos em ensaios de digestibilidade. Revista Brasileira de Zootecnia, v.29, n.3, p.830-835, 2000.

BRITO, R.M.; SAMPAIO, A.A.M.; FERNANDES, A.R.M. et al. Digestibilidades parciais e total de dietas com feno de capimmarandu e concentrado, balanceadas para diferentes níveis de produção. Revista Brasileira de Zootecnia, v.35, n.4, p.1796-1804, 2006 (supl.). 
BÜRGUER, P.J.; PEREIRA, J.C.; VALADARES FILHO, S.C. et al. Fermentação ruminal e eficiência microbiana em bezerros holandeses alimentados com dietas contendo diferentes níveis de concentrado. Revista Brasileira de Zootecnia, v.29, n.1, p.215-224, 2000.

CARDOSO, R.C.; VALADARES FILHO, S.C.; COELHO DA SILVA, J.F. et al. Síntese microbiana, pH e concentração de amônia ruminal e balanço de compostos nitrogenados, em novilhos F1 Limousin-Nelore. Revista Brasileira de Zootecnia, v.29, n.6, p.1844-1852, 2000.

CECAVA, M.J.; MERCHEN, N.R.; GAY, L.C. Composition of ruminal bacteria harvested from steers as influenced by dietary energy level, feeding frequency and isolation techniques. Journal of Dairy Science, v.73, n.9, p.2480-2488, 1990.

CHEN, X.B.; GOMES, M.J. [1995]. Estimation of microbial protein supply to sheep and cattle based on urinary excretion of purine derivatives - an overview of the technical details. Disponível em: < http://www.rri.sri.aj.uk/ ifru>. Acesso: em 10/1/2000.

CHURCH, D.C. El ruminante: fisiologia digestiva e nutrición. 2.ed. Zaragoza: Acribia, 1988. 641p.

CLARK, J.H.; KLUSMEYER, T.H.; CAMERON, M.R. Microbial protein synthesis and flows of nitrogen fractions to the duodenum of dairy cows. Journal of Dairy Science, v.75, n.8, p.2304-2323, 1992.

CRAIG, W.M.; BROWN, D.R.; BRODERICK, G.A. Post prandial compositional changes of fluid and particle associated ruminal microorganisms. Journal of Animal Science, v.65, n.4, p.1042-1048, 1987.

DIAS, H.L.V.; VALADARES FILHO, S.C.; COELHO DA SILVA, J.F. et al. Eficiência da síntese microbiana, pH e concentrações ruminais de amônia em novilhos F1 Limousin-Nelore alimentados com dietas contendo cinco níveis de concentrado. Revista Brasileira de Zootecnia, v.29, n.2, p.555-565, 2000.

FOX, D.G.; SNIFFEN, C.J.; O'CONNOR, J.D. et al. A net carbohydrate and protein system for evaluating cattle diets. III. Cattle requirements and diet adequacy. Journal of Animal Science, v.70, n.10, p.3578-3596, 1992.

FU, C.J.; FELTON, E.E.; LEHMKUHLEI, J.W. et al. Ruminal peptide concentration to optimize microbial growth and efficiency. Journal of Animal Science, v.79, n.5, p.13051312, 2001.

FUNABA, M.; KAGIYAMA, K.; IRIKI, T. et al. Duodenal flow of microbial $\mathrm{N}$ estimated from urinary excretion of purine derivatives in calves after early weaning. Journal of Animal Science, v.75, n.7, p.1965-1973, 1997.

ÍTAVO, L.C.V.; VALADARES FILHO, S.C.; SILVA, F.F. et al. Produção microbiana e parâmetros ruminais de novilhos alimentados com dietas contendo vários níveis de concentrado. Revista Brasileira de Zootecnia, v.31, n.3, p.1553-1561, 2002a (supl.).

ÍTAVO, L.C.V.; VALADARES FILHO, S.C.; SILVA, F.F. et al. Comparação de indicadores e metodologia de coleta para estimativas de produção fecal e fluxo de digesta em bovinos. Revista Brasileira de Zootecnia, v.31, n.4, p.1833-1839, 2002b.

JARRIGE, R. Alimentación de bovinos, ovinos y caprinos. Madri: Mundi-Prensa, 1990. 431p.

LANÇANOVA, J.A.C.; OLIVEIRA, M.D.S.; PACOLA, L.J. et al. Digestibilidade aparente da matéria seca, matéria orgânica e energia bruta e nutrientes digestíveis totais de uma ração completa para bovinos de diferentes grupos genéticos. Revista Brasileira de Zootecnia, v.30, n.3, p.897-903, 2001.

LEÃO, M.I.; COELHO DA SILVA, J.F. Técnica de fistulação de abomaso em bezerros. In: REUNIÃO ANUAL DA SOCIEDADE BRASILEIRA DE ZOOTECNIA, 17., 1980, Fortaleza. Anais... Fortaleza: Sociedade Brasileira de Zootecnia, 1980. p.37.
NATIONAL RESEARCH COUNCIL - NRC. Nutrient requirements of beef cattle. Washington: National Academy Press, 1996. 241p.

PENNING, P.D.; JOHNSON, R.H. The use of internal markers to estimate herbage digestibility and intake. 2. Indigestible acid insoluble fiber. Journal of Agricultural Science, v.100, n.1, p.133-138, 1983.

RENNÓ, L.N.; VALADARES FILHO, S.C.; LEÃO, M.I. Estimativa da produção de proteína microbiana pelos derivados de purinas na urina em novilhos. Revista Brasileira de Zootecnia, v.29, n.4, p.1223-1234, 2000.

RUSSEL, J.B. Strategies that ruminal bacteria use to handle excess carbohydrate. Journal of Animal Science, v.76, n.7, p.19551963, 1998.

SAMPAIO, A.A.M.; VIEIRA, P.F.; BRITO, R.M. Digestão total e parcial de nutrientes em bovinos alimentados com ração contendo levedura, uréia e farelo de algodão. Revista Brasileira de Zootecnia, v.29, n.2, p.589-597, 2000.

SAMPAIO, I.B.M. Estatística aplicada à experimentação animal. Belo Horizonte: Fundação de Ensino e Pesquisa em Medicina Veterinária e Zootecnia, 1998. 221p.

SNIFFEN, C.J.; O'CONNOR, J.D.; van SOEST, P.J. et al. A net carbohydrate and protein system for evaluating cattle diets: II. Carbohydrate and protein availability. Journal of Animal Science, v.70, n.11, p.3562-3577, 1992.

TIBO, G.C.; VALADARES FILHO, S.C.; VALADARES, R.F.D. et al. Níveis de concentrado em dietas de novilhos mestiços F1 Simental-Nelore. 2. Balanço nitrogenado, eficiência microbiana e parâmetros ruminais. Revista Brasileira de Zootecnia, v.29, n.3, p.921-929, 2000.

VAGNONI, D.B.; BRODERICK, G.A.; CLAYTON, M.K. et al. Excretion of purine derivates by Holstein cows abomasally infused with incremental amounts of purines. Journal of Dairy Science, v.80, n.8, p.1695-1702, 1997.

VALADARES FILHO, S.C. Eficiência de síntese de proteína microbiana, degradação ruminal e digestibilidade intestinal da proteína bruta em bovinos. In: SIMPÓSIO INTERNACIONAL SOBRE EXIGÊNCIAS NUTRICIONAIS DE RUMINANTES, 1., 1995, Viçosa, MG. Anais... Viçosa, MG: Universidade Federal de Viçosa, 1995. p.355-388.

VALADARES FILHO, S.C.; SILVA, J.F.C.; LEÃO, M.I. et al. Eficiência de síntese microbiana em novilhos holandeses, nelores e búfalos mestiços, obtida por diferentes métodos. Revista da Sociedade Brasileira de Zootecnia, v.19, n.5, p.424-430, 1990.

Van SOEST, P.J.; WINE, R.H. Use of detergent in the analysis of fibrous feeds. IV. Determination of plant-cell wall constituents. Journal of Animal Science, v.76, n.10, p.2717-2729, 1998

VÉRAS, A.S.C.; VALADARES FILHO, S.C.; COELHO DA SILVA, J.F. et al. Consumo e digestibilidade aparente em bovinos Nelore, não-castrados, alimentados com rações contendo diferentes níveis de concentrado. Revista Brasileira de Zootecnia, v.29, n.6, p.2367-2378, 2000 (supl. 2).

VERBIC, J.; CHEN, X.B.; MACLEOD, N.A. et al. Excretion of purine derivatives by ruminants - Effect of microbial nucleic acid infusion on purine derivative excretion by steers. Journal of Agricultural Science, v.114, n.3, p.243-248, 1990.

ZINN, R.A.; OWENS, F.N. A rapid procedure for purine measurement and its use for estimating net ruminal protein synthesis. Canadian Journal of Animal Science, v.66, n.1, p.157-165, 1986. 